\title{
Percutaneous coronary intervention strategies and prognosis for graft lesions following coronary artery bypass grafting
}

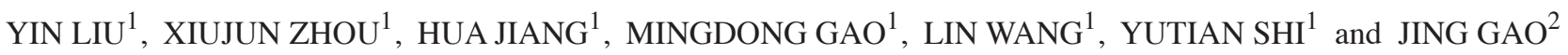 \\ ${ }^{1}$ Department of Cardiology; ${ }^{2}$ Cardiovascular Institute, Department of Cardiology, \\ Tianjin Chest Hospital, Tianjin 300051, P.R. China
}

Received May 24, 2014; Accepted January 9, 2015

DOI: 10.3892/etm.2015.2366

\begin{abstract}
The purpose of this study was to compare the prognosis of graft-percutaneous coronary intervention (PCI) and native vessel (NV)-PCI, drug-eluting stents (DESs) and bare-metal stents (BMSs) for the treatment of graft lesions following coronary artery bypass grafting (CABG), and to determine the risk factors for major adverse cardiac events (MACEs). A total of 289 patients who underwent PCI following CABG between August 2005 and March 2010 were retrospectively analyzed. The effects on survival were compared among patients who underwent NV- and graft-PCI, and DES and BMS implantation. Additionally, the risk factors for MACEs following PCI for graft lesions were analyzed. The findings showed that MACE-free and revascularization-free survival rates were significantly higher in the NV-PCI group compared with those in the graft-PCI group. There were 63 cases $(29.0 \%)$ of MACEs in the DES group and 25 cases (52.1\%) in the BMS group. In patients undergoing NV-PCI, the DES group had significantly fewer MACEs and less target vessel revascularization (TVR) than the BMS group. In patients undergoing graft-PCI, the DES group showed a tendency for fewer MACEs and a lower incidence of cardiac mortality, myocardial infarction and TVR compared with the BMS group. Diabetes, an age of $>70$ years and graft-PCI were independent risk factors for MACEs in patients post-PCI. It is concluded that NV-PCI has superior long-term outcomes compared with graft-PCI, and should therefore be considered as the first-line treatment for graft disease following CABG. Despite this, graft-PCI remains a viable option. DESs are the first choice for graft-PCI due to their safety and efficacy and their association with reduced mortality and MACE rate. Diabetes, older age and graft-PCI are independent risk factors for MACEs in patients post-CABG who are undergoing revascularization.
\end{abstract}

Correspondence to: $\mathrm{Dr}$ Jing Gao, Cardiovascular Institute, Department of Cardiology, Tianjin Chest Hospital, 261 Taierzhuang South Road, Jinnan, Tianjin 300051, P.R. China

E-mail: gaojing2088@163.com

Key words: coronary artery bypass grafting, percutaneous coronary intervention, multivariate risk factors, prognosis, follow-up

\section{Introduction}

The annual percentage of recurrences following coronary artery bypass graft (CABG) surgery that require further revascularization therapy, is $\sim 8.6-10.4 \%$ (1). Patients with CABG have a tendency to survive longer, leading to the issue of decreased long term patency rates. The native coronary artery may also develop de novo atherosclerosis, resulting in myocardial ischemia and angina. The 10 -year patency rate of the internal mammary artery graft is $85-95 \%$, whereas the 10-year patency rate of saphenous vein grafts (SVG) is only $\sim 40 \%$ (2-5). Furthermore, $40 \%$ of patients with not yet occluded SVG experience various extents of stenosis, the treatment of which has become a common clinical problem (6-8). Graft stenosis can be treated with secondary CABG or percutaneous coronary intervention (PCI) in either the native vessel (NV) or the graft. With significantly increased mortality, incidence of myocardial infarction, and perioperative complications, the benefit of secondary CABG is much lower, as compared with first-time CABG. Therefore, PCI has become the preferential option for revascularization following CABG treatment (9-10). The optimal percutaneous revascularization strategy for patients with SVG disease subsequent to $\mathrm{CABG}$ remains unclear and the results obtained by previous retrospective studies are controversial (11-17); thus, two questions remain unanswered. The first is the choice of target vessel for either the graft or the native coronary artery. The second is whether to use a drug eluting stent (DES) or bare metal stent (BMS) for the PCI. The present study analyzed the clinical and pathological manifestations of patients receiving post-CABG PCI treatment. Furthermore, the risk factors for major adverse cardiac events (MACEs) in patients subjected to $\mathrm{PCI}$ post-CABG were investigated and the treatment strategy and prognosis were discussed.

\section{Materials and methods}

Study design. Patients undergoing PCI for graft lesions post-CABG, as demonstrated by ischemic symptoms or on angiography, were investigated in the present study. The patients were treated at the Tianjin Chest Hospital (Tianjin, China) between August 2005 and March 2010 and included 211 males and 78 females with a mean age of $63.21 \pm 8.44$ years. All demographic characteristics, cardiac risk factors, clinical 
presentations, angiographic and procedural results and in-hospital outcomes were prospectively recorded in cardiovascular databases. Baseline patient demographic data are shown in Table I. Patients with the following characteristics were excluded: i) Liver or renal dysfunction; ii) allergy or intolerance to aspirin or clopidogrel; iii) PCI in both the NV and graft; iv) implanted with both DES and BMS. The study protocol was approved by the Ethics Committee of Tianjin Chest Hospital. Written informed consent was obtained from all of the patients.

PCI procedure. Prior to the procedure, $300 \mathrm{mg} /$ day aspirin and 300-600 mg clopidogrel were administered once. Quantitative coronary angiographic analysis was performed using a validated, edge-detection system (Medcon QCA software; Medcon Ltd., Tel Aviv, Israel). All PCIs were carried out according to the practices and preferences of the surgeon involved. This included the selection of either a BMS or a DES and the anticoagulation therapy utilized [heparin or bivalirudin, and the use of a glycoprotein IIb/IIIa (GpIIb/IIIa) inhibitor]. Embolic protection devices, if technically feasible, were used on a routine basis for SVG interventions. The standard for a successful surgery was defined as a final residual stenosis of $<20 \%$ and thrombolysis in myocardial infarction (MI) flow grade 3 . Following the procedure, aspirin was administered indefinitely. Clopidogrel (75 mg/day) was initially recommended for $\geq 6$ months after DES implantation or for $\geq 3$ months after BMS implantation. Since December 2006, a minimum of 1 year of clopidogrel has been recommended subsequent to DES placement (18).

Clinical follow-up and study end-points. Patients undergoing stent implantation at the Tianjin Chest Hospital are routinely followed-up at 6 months, 1 year and annually thereafter by telephone interviews with the patient or family and a review of the medical records. The primary study end-point was all-cause mortality. The secondary study end-point was a composite end-point of one of the following MACEs: Cardiac mortality, non-fatal MI or target vessel revascularization (TVR). MI was defined as the onset of chest pain in combination with new, typical changes in the electrocardiogram and biochemical evidence of myocardial necrosis. Since MIs recorded during the follow-up period could have occurred in any region of the myocardium it was not possible to establish whether the MI was specific to the stented SVG segment. Target lesion revascularization (TLR) was defined as the requirement for a repeated revascularization procedure (either PCI or coronary bypass surgery) due to re-stenosis in the stented segment. TVR was defined as a new revascularization procedure in the target vessel, and also included TLR. Any clinical events arising throughout the study were adjudicated by an independent clinical events committee that was blinded to the treatment assigned to the patient.

Statistical analysis. Continuous variables are expressed as the mean \pm standard deviation and were compared with the Student's t-test. Categorical variables are expressed as frequencies and were compared using the $\chi^{2}$ or Fisher's exact test. The effects on survival were compared between the NV-PCI and graft-PCI, and DES and BMS groups using the
Table I. Baseline clinical characteristics of the study population.

\begin{tabular}{|c|c|}
\hline Clinical characteristic & Value \\
\hline Age, years ${ }^{\mathrm{a}}$ & $63.21 \pm 8.44$ \\
\hline Male, $\mathrm{n}(\%)$ & $211(73.01)$ \\
\hline Hypertension, n (\%) & $186(64.36)$ \\
\hline Diabetes mellitus, n (\%) & $154(53.29)$ \\
\hline Hypercholesterolemia, n (\%) & $193(66.78)$ \\
\hline Smoking, n (\%) & $154(53.29)$ \\
\hline Previous MI, n (\%) & $115(39.80)$ \\
\hline Previous PCI, n (\%) & $61(21.11)$ \\
\hline \multicolumn{2}{|l|}{ Form of CHD } \\
\hline $\mathrm{SA}, \mathrm{n}(\%)$ & $41(14.19)$ \\
\hline $\mathrm{UA}, \mathrm{n}(\%)$ & $185(64.01)$ \\
\hline STEMI, n (\%) & $34(11.76)$ \\
\hline NSTEMI, n (\%) & $29(10.03)$ \\
\hline $\mathrm{BMI}, \mathrm{kg} / \mathrm{m}^{2 \mathrm{a}}$ & $25.99 \pm 3.27$ \\
\hline $\mathrm{FBG}, \mathrm{mmol} / \mathrm{l}^{\mathrm{a}}$ & $6.48 \pm 2.07$ \\
\hline $\mathrm{FIB}, \mathrm{g} / \mathrm{l}^{\mathrm{a}}$ & $3.64 \pm 1.03$ \\
\hline $\mathrm{CHO}, \mathrm{mmol} / \mathrm{l}^{\mathrm{a}}$ & $4.80 \pm 1.16$ \\
\hline $\mathrm{TG}, \mathrm{mmol} / \mathrm{l}^{\mathrm{a}}$ & $2.01 \pm 1.51$ \\
\hline $\mathrm{HDL}-\mathrm{C}, \mathrm{mmol} / \mathrm{l}^{\mathrm{a}}$ & $1.13 \pm 0.30$ \\
\hline $\mathrm{LDL}-\mathrm{C}, \mathrm{mmol} / \mathrm{l}^{\mathrm{a}}$ & $2.72 \pm 0.74$ \\
\hline LVEF, $\%^{\mathrm{a}}$ & $56.80 \pm 7.03$ \\
\hline Graft age, months ${ }^{\mathrm{a}}$ & $50.00 \pm 29.12$ \\
\hline
\end{tabular}

aresented as the mean \pm standard deviation. MI, myocardial infarction; PCI, percutaneous coronary intervention; CHD, coronary heart disease; SA, stable angina; UA, unstable angina; STEMI, ST segment elevation myocardial infarction; NSTEMI, non-ST segment elevation myocardial infarction; BMI, body mass index; FBG, fasting blood glucose; FIB, fibrinogen; $\mathrm{CHO}$, cholesterol; TG, triglyceride; HDL-C, high-density lipoprotein cholesterol; LDL-C, low-density lipoprotein cholesterol; LVEF, left ventricular ejection fraction.

Kaplan-Meier survival curve and log-rank test. Risk factors for MACEs post-PCI were analyzed with multivariable Cox regression models. Odds ratios (ORs) and the $95 \%$ confidence intervals (95\% CIs) were used to express relative risk. SPSS software (version 18.0; SPSS Inc., Chicago, IL, USA) was used for the statistical analysis. All the tests were two-tailed, and $\mathrm{P}<0.05$ was considered to indicate a statistically significant difference.

\section{Results}

Baseline clinical characteristics. Baseline patient demographic data are listed in Table I.

Long-term follow-up outcomes. Among the 289 cases, only 24 were lost to follow-up ( $8.3 \%)$, leaving a total of 265 patients who were followed. The mean follow-up time was 37 months (range, 6-78 months). Eighty-eight cases of MACEs occurred 


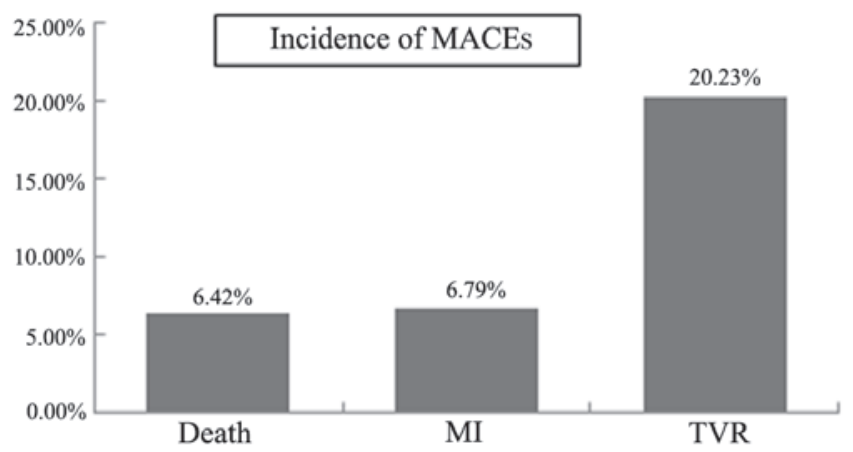

Figure 1. Overall long-term outcomes: MACEs. MACE, major adverse cardiac event; MI, myocardial infarction; TVR, target vessel revascularization.

(33.2\%), including 17 cardiac mortalities (6.4\%), 18 MIs (6.8\%) and 53 cases of TVR (20.0\%) (Fig. 1).

Comparison of different PCI strategies. NV-PCI was performed in 202 patients $(69.9 \%)$ and graft-PCI in 87 patients $(30.1 \%)$. Compared with the NV-PCI group, the graft-PCI group had more completely occluded NVs and fewer completely occluded grafts, larger diameters of the smallest stents and shorter stent lengths. Clinical baseline, angiographic and procedural data of the two groups are shown in Table II. Two hundred sixty-five patients were followed up for a mean time of 37 months, including 190 patients in the NV-PCI group and 75 patients in the graft-PCI group. MACEs occurred in 54 patients in the NV-PCI group (28.4\%) and 34 patients in the graft-PCI group $(45.3 \%)$. The NV-PCI group had a higher MACE-free and revascularization-free survival compared with the graft-PCI group (71.6 vs. 54.7\%, log-rank $\mathrm{P}=0.008 ; 82.6$ vs. $73.3 \%$, log-rank $\mathrm{P}=0.048$, respectively). No significant difference was found in the overall survival and MI-free survival between the groups (94.7 vs. 90.7\%, log-rank $\mathrm{P}=0.099 ; 94.2$ vs. $90.7 \%$, log-rank $\mathrm{P}=0.124$, respectively) (Fig. 2).

Comparison of the stent types for PCI. DESs were used in 239 patients $(82.7 \%)$ and BMSs in 50 patients $(17.3 \%)$. Patients in the BMS group were older compared with those in the DMS group. The groups did not differ significantly in the number of occluded NVs or grafts $(\mathrm{P}>0.05)$. The BMS group had larger stent diameters but fewer stents (both $\mathrm{P}<0.05)$. Baseline clinical, angiographic and procedural data of the two groups are listed in Table III. Of the 265 patients who completed the long-term follow-up, 217 were in the DES group and 48 in the BMS group. There were 63 occurrences (29.0\%) of MACEs in the DES group and 25 (52.1\%) in the BMS group. The DES group had a higher MACE-free and MI-free survival compared with the BMS group (71.0 vs. $47.9 \%$, log-rank $\mathrm{P}=0.013$; 94.9 vs. $85.4 \%$, log-rank $\mathrm{P}=0.028$, respectively). No significant difference was found in the overall and revascularization-free survival (95.9 vs. 89.6\%, log-rank $\mathrm{P}=0.356 ; 81.6$ vs. $72.9 \%$, log-rank $\mathrm{P}=0.386$, respectively) (Fig. 3).

Stent performance according to intervention strategy. In the 190 patients undergoing NV-PCI, DESs were implanted in 161 patients $(84.7 \%)$ and BMSs in 29 (15.3\%). The inci- dence rates of MACEs and TVR in patients with DESs were significantly lower than those in patients with BMSs (24.2 vs. $51.7 \%, \mathrm{P}=0.003 ; 14.9$ vs. $31.0 \%, \mathrm{P}=0.035$, respectively), while the incidence of mortality and $\mathrm{MI}$ (4.4 vs. $10.3 \%, \mathrm{P}=0.182$; 5.0 vs. $10.3 \%, P=0.254$, respectively) did not differ significantly between the two groups. In the 75 patients undergoing graft-PCI, DESs were implanted in 56 patients (74.7\%) and BMSs in 19 patients (25.3\%). The DES group showed a tendency for lower incidence rates of MACEs (42.9 vs. 52.6\%, $\mathrm{P}=0.460)$, cardiac mortality (8.9 vs. $10.5 \%, \mathrm{P}=0.836)$, $\mathrm{MI}(7.1$ vs. $15.8 \%, \mathrm{P}=0.360)$ and TVR $(25.0$ vs. $31.6 \%, \mathrm{P}=0.575)$.

Risk factors for MACEs post-PCI. The following factors were considered to be independent variables in the multivariable Cox regression model analysis of risk factors for MACEs subsequent to PCI: Site of the PCI (NV or graft), age of $>70$ years, gender, diabetes, graft age of $>5$ years, use of a GpIIb/IIIa inhibitor, embolic protection device, number of completely occluded NVs or grafts, stent type, mean minimal stent diameter and mean total stent length. Diabetes, age $>70$ years and graft-PCI were independent risk factors for the development of MACEs (Table IV).

\section{Discussion}

The 10-year patency rate of the internal mammary artery graft has been previously reported to be $85-95 \%$ (5) compared with only $40 \%$ for SVGs (6). Approximately $40 \%$ of unoccluded SVGs may develop stenosis (6). Patients with diseased graft vessels are older and the primary coronary lesion prior to CABG is often severe (10).

Grafts, and particularly SVGs, usually deteriorate within 3 years, resulting in ischemia and refractory heart failure with a poor prognosis (19). Graft lesions following CABG have remained an important clinical challenge. Graft revascularization can be achieved with a second CABG or PCI; however, a second $\mathrm{CABG}$ can be difficult, with an increased incidence of complications and mortality, and inferior results with regard to symptom relief, graft patency and event-free survival (20). Older age, systematic atherosclerosis, vital organ dysfunction and malignancy are also contraindications for a second CABG. In addition, potential donor sites for a new graft are sparse following two or more attempts at CABG. PCI has therefore become the preferred mode of treatment for graft lesions, the majority of which are SVGs (10). PCI has also become the first-line treatment for post-CABG myocardial ischemia due to its excellent safety and efficacy (21-22).

NV-PCI and graft-PCI are the two options for graft revascularization following $\mathrm{CABG}$. Graft-PCI shows superior outcomes to repeated CABG; however, graft-PCI is complex due to the anatomy of the saphenous vein and results in low success rates (23). Graft-PCI is easily complicated by distal thrombosis during the procedure, post-procedural re-stenosis and unconfirmed long-term efficacy; therefore, current guidelines do not recommend PCI for the treatment of completely occluded grafts $(22,24,25)$. PCI for graft stenosis is optional when the NV is totally occluded, has diffuse lesions, failed opening or is unlikely to open, as judged by the surgeon. With sufficient training and a good surgical technique, NV-PCI does not require highly specialized instrumentation and, with 
Table II. Comparison of baseline and procedural characteristics according to PCI strategy.

\begin{tabular}{|c|c|c|c|}
\hline Clinical characteristic & NV-PCI & Graft-PCI & P-value \\
\hline Age, years ${ }^{\mathrm{a}}$ & $63.78 \pm 8.58$ & $61.90 \pm 8.01$ & 0.082 \\
\hline Male, n (\%) & $152(75.25)$ & $59(67.82)$ & 0.192 \\
\hline Hypertension, n (\%) & $131(64.85)$ & $55(63.22)$ & 0.790 \\
\hline Diabetes mellitus, n (\%) & $109(53.96)$ & $45(51.72)$ & 0.727 \\
\hline Hypercholesterolemia, n (\%) & $139(68.81)$ & $54(62.07)$ & 0.264 \\
\hline Smoking, n (\%) & $103(51.00)$ & $51(58.62)$ & 0.283 \\
\hline Previous MI, n (\%) & $80(39.60)$ & $35(40.23)$ & 0.921 \\
\hline Previous PCI, n (\%) & $43(21.30)$ & $18(20.69)$ & 0.909 \\
\hline \multicolumn{4}{|l|}{ Form of CHD } \\
\hline $\mathrm{SA}, \mathrm{n}(\%)$ & $32(15.84)$ & $9(10.34)$ & 0.219 \\
\hline $\mathrm{UA}, \mathrm{n}(\%)$ & $130(64.36)$ & $55(63.22)$ & 0.853 \\
\hline STEMI, n (\%) & $19(9.41)$ & $15(17.24)$ & 0.058 \\
\hline NSTEMI, n (\%) & $21(10.40)$ & $8(9.20)$ & 0.755 \\
\hline BMI, $\mathrm{kg} / \mathrm{m}^{2 \mathrm{a}}$ & $26.06 \pm 3.27$ & $25.83 \pm 3.26$ & 0.573 \\
\hline $\mathrm{FBG}, \mathrm{mmol} / \mathrm{l}^{\mathrm{a}}$ & $6.36 \pm 1.96$ & $6.77 \pm 2.27$ & 0.116 \\
\hline $\mathrm{FIB}, \mathrm{g} / \mathrm{l}^{\mathrm{a}}$ & $3.64 \pm 1.01$ & $3.65 \pm 1.07$ & 0.933 \\
\hline $\mathrm{CHO}, \mathrm{mmol} / \mathrm{l}^{\mathrm{a}}$ & $4.80 \pm 1.23$ & $4.82 \pm 0.97$ & 0.904 \\
\hline $\mathrm{TG}, \mathrm{mmol} / \mathrm{l}^{\mathrm{a}}$ & $1.82 \pm 1.20$ & $2.47 \pm 2.03$ & 0.001 \\
\hline $\mathrm{HDL}-\mathrm{C}, \mathrm{mmol} / \mathrm{l}^{\mathrm{a}}$ & $1.13 \pm 0.31$ & $1.12 \pm 0.30$ & 0.757 \\
\hline $\mathrm{LDL}-\mathrm{C}, \mathrm{mmol} / \mathrm{l}^{\mathrm{a}}$ & $2.73 \pm 0.75$ & $2.68 \pm 0.69$ & 0.537 \\
\hline $\mathrm{LVEF}, \%^{\mathrm{a}}$ & $56.74 \pm 6.23$ & $56.94 \pm 8.64$ & 0.825 \\
\hline Graft age, months ${ }^{\mathrm{a}}$ & $48.50 \pm 31.40$ & $53.45 \pm 22.75$ & 0.185 \\
\hline \multicolumn{4}{|l|}{ Number of occluded NVs, n (\%) } \\
\hline 0 & $110(54.46)$ & $28(32.18)$ & 0.001 \\
\hline 1 & $40(19.80)$ & $19(21.84)$ & 0.694 \\
\hline 2 & $32(15.84)$ & $21(24.14)$ & 0.095 \\
\hline$\geq 3$ & $20(9.90)$ & $19(21.84)$ & 0.006 \\
\hline \multicolumn{4}{|l|}{ Number of occluded grafts, n (\%) } \\
\hline 0 & $64(31.68)$ & $35(40.23)$ & 0.160 \\
\hline 1 & $66(32.67)$ & $38(43.68)$ & 0.074 \\
\hline 2 & $36(17.82)$ & $7(8.05)$ & 0.032 \\
\hline$\geq 3$ & $36(17.82)$ & $7(8.05)$ & 0.032 \\
\hline Number of stents ${ }^{\mathrm{a}}$ & $2.24 \pm 1.12$ & $2.15 \pm 1.14$ & 0.544 \\
\hline Minimal stent diameter, $\mathrm{mm}^{\mathrm{a}}$ & $2.95 \pm 0.69$ & $3.17 \pm 0.58$ & 0.008 \\
\hline Total stent length, $\mathrm{mm}^{\mathrm{a}}$ & $45.35 \pm 22.14$ & $39.29 \pm 19.92$ & 0.029 \\
\hline GpIIb/IIIa inhibitor, n (\%) & $54(26.73)$ & $26(29.89)$ & 0.583 \\
\hline Embolic protection device, n (\%) & - & $31(35.63)$ & NA \\
\hline Complete revascularization, $\mathrm{n}(\%)$ & $53(26.24)$ & $18(20.60)$ & 0.315 \\
\hline
\end{tabular}

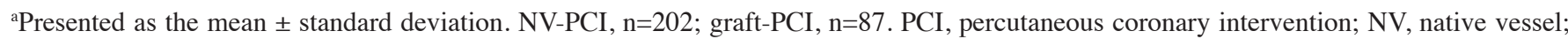
MI, myocardial infarction; CHD, coronary heart disease; SA, stable angina; UA, unstable angina; STEMI, ST segment elevation myocardial infarction; NSTEMI, non-ST segment elevation myocardial infarction; BMI, body mass index; FBG, fasting blood glucose; FIB, fibrinogen; $\mathrm{CHO}$, cholesterol; TG, triglyceride; HDL-C, high-density lipoprotein cholesterol; LDL-C, low-density lipoprotein cholesterol; LVEF, left ventricular ejection fraction; GpIIb/IIIa, glycoprotein IIb/IIIa; NA, not applicable.

sufficient training, it is a straightforward surgical procedure. Compared with graft-PCI, NV-PCI has a higher success rate in complicated coronary disease (26). The reopened native coronary artery is preferred due to its long-term durability 
Table III. Comparison of baseline and procedural characteristics according to type of stent implanted.

\begin{tabular}{|c|c|c|c|}
\hline Clinical characteristic & DES & BMS & P-value \\
\hline Age, years ${ }^{\mathrm{a}}$ & $62.01 \pm 8.25$ & $72.72 \pm 4.11$ & 0.000 \\
\hline Male, n (\%) & $188(74.60)$ & $23(62.16)$ & 0.111 \\
\hline Hypertension, n (\%) & $160(63.49)$ & $26(70.27)$ & 0.421 \\
\hline Diabetes mellitus, n (\%) & $128(50.79)$ & $26(70.27)$ & 0.027 \\
\hline Hypercholesterolemia, n (\%) & $164(65.08)$ & $29(78.38)$ & 0.109 \\
\hline Smoking, n (\%) & $136(53.97)$ & $18(48.65)$ & 0.545 \\
\hline Previous MI, n (\%) & $96(38.10)$ & $16(43.24)$ & 0.124 \\
\hline Previous PCI, n (\%) & $50(19.84)$ & $11(29.73)$ & 0.169 \\
\hline \multicolumn{4}{|l|}{ Form of CHD } \\
\hline $\mathrm{SA}, \mathrm{n}(\%)$ & $35(13.89)$ & $6(16.22)$ & 0.705 \\
\hline $\mathrm{UA}, \mathrm{n}(\%)$ & $162(64.29)$ & $23(62.16)$ & 0.802 \\
\hline STEMI, n (\%) & $30(11.90)$ & $4(10.81)$ & 1.000 \\
\hline NSTEMI, n (\%) & $25(9.92)$ & $4(10.81)$ & 0.775 \\
\hline BMI, $\mathrm{kg} / \mathrm{m}^{2 \mathrm{a}}$ & $25.97 \pm 3.19$ & $26.14 \pm 3.81$ & 0.767 \\
\hline $\mathrm{FBG}, \mathrm{mmol} / \mathrm{l}^{\mathrm{a}}$ & $6.52 \pm 2.08$ & $6.15 \pm 2.01$ & 0.263 \\
\hline $\mathrm{FIB}, \mathrm{g} / \mathrm{l}^{\mathrm{a}}$ & $3.67 \pm 1.00$ & $3.54 \pm 1.13$ & 0.832 \\
\hline $\mathrm{CHO}, \mathrm{mmol} / \mathrm{l}^{\mathrm{a}}$ & $4.69 \pm 1.03$ & $5.56 \pm 1.61$ & 0.000 \\
\hline $\mathrm{TG}, \mathrm{mmol} / \mathrm{l}^{\mathrm{a}}$ & $2.02 \pm 1.54$ & $1.94 \pm 1.28$ & 0.716 \\
\hline $\mathrm{HDL}-\mathrm{C}, \mathrm{mmol} / \mathrm{l}^{\mathrm{a}}$ & $1.12 \pm 0.31$ & $1.15 \pm 0.27$ & 0.632 \\
\hline $\mathrm{LDL}-\mathrm{C}, \mathrm{mmol} / \mathrm{l}^{\mathrm{a}}$ & $2.70 \pm 0.73$ & $2.82 \pm 0.75$ & 0.350 \\
\hline $\mathrm{LVEF}, \%{ }^{\mathrm{a}}$ & $56.91 \pm 7.14$ & $56.05 \pm 6.25$ & 0.489 \\
\hline Graft age, months & $49.67 \pm 28.03$ & $52.14 \pm 36.01$ & 0.631 \\
\hline \multicolumn{4}{|l|}{ Number of occluded NVs, n (\%) } \\
\hline 0 & $120(47.62)$ & $18(48.65)$ & 0.907 \\
\hline 1 & $54(21.43)$ & $5(13.51)$ & 0.265 \\
\hline 2 & $41(16.27)$ & $12(32.43)$ & 0.018 \\
\hline$\geq 3$ & $37(14.68)$ & $2(5.41)$ & 0.194 \\
\hline \multicolumn{4}{|l|}{ Number of occluded grafts, n (\%) } \\
\hline 0 & $88(34.92)$ & $11(29.73)$ & 0.534 \\
\hline 1 & $88(34.92)$ & $16(43.24)$ & 0.325 \\
\hline 2 & $37(14.68)$ & $6(16.22)$ & 0.807 \\
\hline$\geq 3$ & $39(15.48)$ & $4(10.81)$ & 0.457 \\
\hline Number of stents ${ }^{\mathrm{a}}$ & $2.26 \pm 1.15$ & $1.86 \pm 0.82$ & 0.045 \\
\hline Minimal stent diameter, $\mathrm{mm}^{\mathrm{a}}$ & $2.98 \pm 0.65$ & $3.28 \pm 0.71$ & 0.010 \\
\hline Total stent length, $\mathrm{mm}^{\mathrm{a}}$ & $44.26 \pm 22.34$ & $38.51 \pm 15.40$ & 0.132 \\
\hline GpIIb/IIIa inhibitor, n (\%) & $71(28.17)$ & $9(24.32)$ & 0.625 \\
\hline Embolic protection device, n (\%) & $24(10.04)$ & $7(14.00)$ & 0.411 \\
\hline Complete revascularization, $\mathrm{n}(\%)$ & $60(25.10)$ & $11(22.00)$ & 0.643 \\
\hline
\end{tabular}

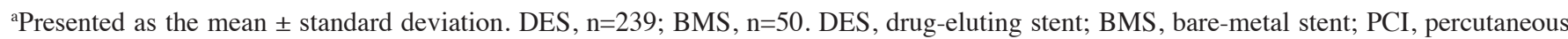
coronary intervention; NV, native vessel; MI, myocardial infarction; CHD, coronary heart disease; SA, stable angina; UA, unstable angina; STEMI, ST segment elevation myocardial infarction; NSTEMI, non-ST segment elevation myocardial infarction; BMI, body mass index; FBG, fasting blood glucose; FIB, fibrinogen; $\mathrm{CHO}$, cholesterol; TG, triglyceride; HDL-C, high-density lipoprotein cholesterol; LDL-C, low-density lipoprotein cholesterol; LVEF, left ventricular ejection fraction; GpIIb/IIIa, glycoprotein IIb/III.

compared with the degenerated SVG; however, the complexity of NV lesions affects the success rate of PCI (11-13).
Comparison studies of different PCI strategies for post-CABG graft lesions show conflicting findings (27-29). 
A

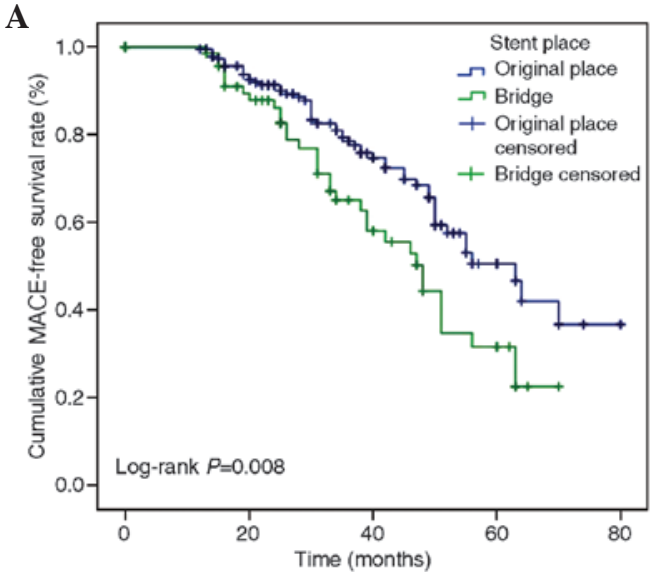

C

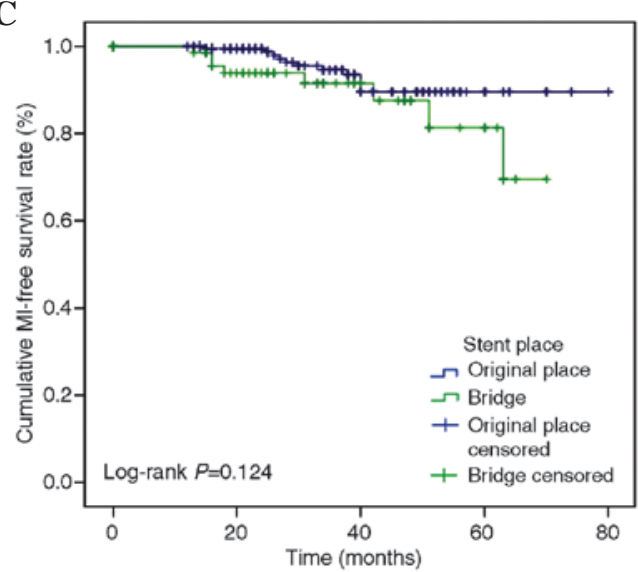

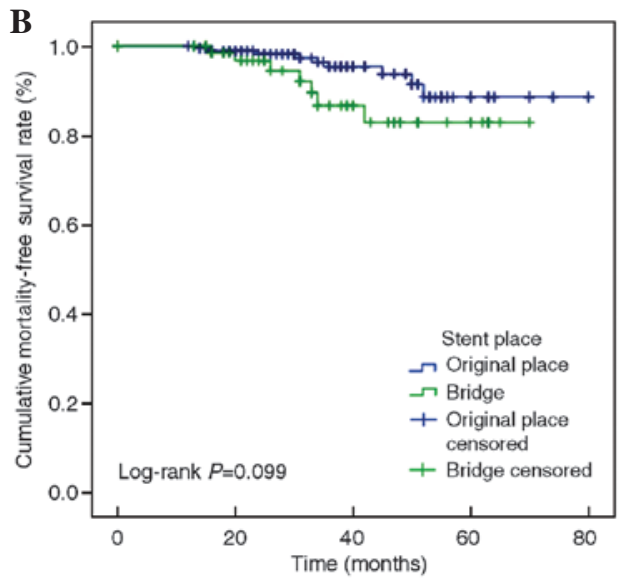

D

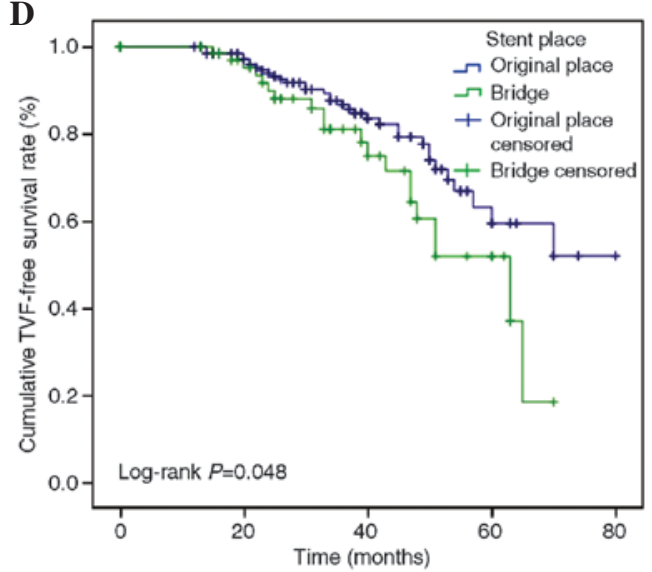

Figure 2. Kaplan-Meier survival curves at clinical follow-up based on percutaneous coronary intervention strategy. (A) MACE-free, (B) mortality-free, (C) MI-free and (D) revascularization-free survival rates. MACE, major adverse cardiac event; MI, myocardial infarction; TVF, target vessel failure.

A
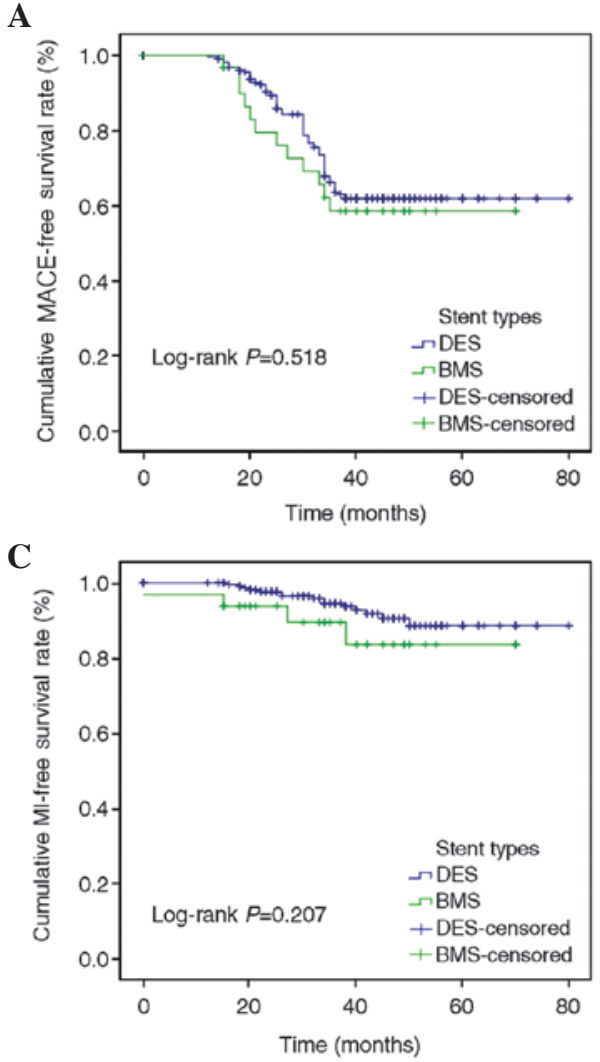

B

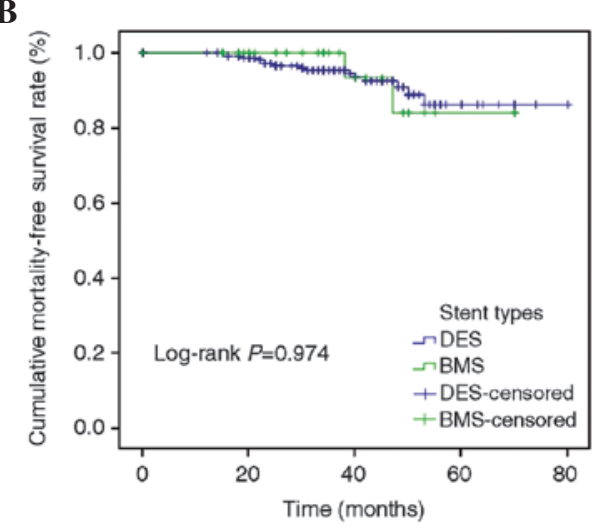

D

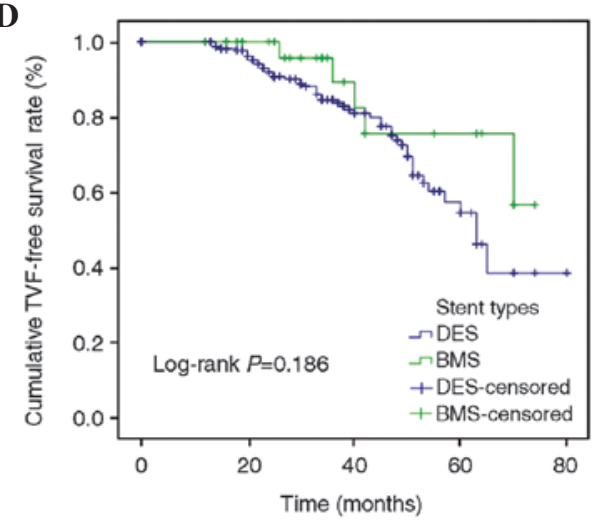

Figure 3. Kaplan-Meier survival curves at clinical follow-up based on stent type. (A) MACE-free, (B) mortality-free, (C) MI-free and (D) revascularization-free survival rates. MACE, major adverse cardiac event; MI, myocardial infarction; TVF, target vessel failure. 
Table IV. Analysis of risk factors for major adverse cardiac events.

\begin{tabular}{lcccccr}
\hline Variables & $\beta$ & SE & Wald & OR & 95\% CI & P-value \\
\hline Diabetes & 0.193 & 0.242 & 0.636 & 1.213 & $1.056-1.950$ & 0.045 \\
Age $>$ 70 years & 0.325 & 0.291 & 1.249 & 1.384 & $1.123-2.448$ & 0.037 \\
Graft age $>5$ years & 0.092 & 0.243 & 0.144 & 1.096 & $0.681-1.764$ & 0.704 \\
Occluded graft $\geq 2$ & 0.016 & 0.282 & 0.003 & 1.016 & $0.585-1.765$ & 0.954 \\
Occluded NV $\geq 2$ & 0.051 & 0.265 & 0.037 & 1.052 & $0.626-1.767$ & 0.847 \\
Graft-PCI & 0.796 & 0.284 & 7.851 & 2.218 & $1.270-3.871$ & 0.005 \\
DES & 0.028 & 0.418 & 0.004 & 0.973 & $0.429-2.205$ & 0.947 \\
GpIIb/IIIa & 0.561 & 0.124 & 0.678 & 1.122 & $0.672-2.342$ & 0.543 \\
Embolic protection device & 0.432 & 0.098 & 0.754 & 0.876 & $0.544-1.434$ & 0.786 \\
Stent diameter & 0.319 & 0.171 & 3.497 & 0.876 & $0.817-1.092$ & 0.061 \\
Stent length & 0.006 & 0.012 & 0.288 & 1.006 & $0.984-1.029$ & 0.592
\end{tabular}

HR, hazard ratio; OR, odds ratio; CI, confidence interval; SE, standard error; NV, native vessel; PCI, percutaneous coronary intervention; DES, drug-eluting stent; GpIIb/IIIa, glycoprotein IIb/III.

In a study with 1,000 patients with a mean follow-up time of 29 months, SVG-PCI was shown to have a 2.1-fold mortality risk and 1.6-fold MACE occurrence compared with NV-PCI (27). In a prospective study including 190 patients with post-CABG NV-PCI and 88 patients with graft-PCI, the graft-PCI group had significantly higher incidence rates of MACEs, mortality and TVR than the NV-PCI group (43.2 vs. $19.6 \%$, log-rank $\mathrm{P}<0.001 ; 19.3$ vs. $6.9 \%$, log-rank $\mathrm{P}=0.008$; 23.9 vs. $12.7 \%, \log$-rank $\mathrm{P}=0.02$, respectively), and graft-PCI was shown to be an independent risk factor for MACEs [hazard ratio (HR), 2.84; 95\% CI, 1.45-5.57; $\mathrm{P}=0.002$ ] (21). By contrast, in a retrospective study of 618 patients subjected to PCI post-CABG with a mean follow-up time of 27 months, the NV-PCI and SVG-PCI groups did not show significant differences in the incidence rates of mortality (10.0 vs. $8.0 \%$, $\mathrm{P}=0.22)$, MI (9.0 vs. $6.0 \%, \mathrm{P}=0.20)$ or TVR (26.0 vs. $25.0 \%$, $\mathrm{P}=0.80)(29)$.

In the present study, 265 patients completed the follow-up, with a significantly higher proportion of NV-PCI cases than graft-PCI cases (190 NV-PCI and 75 graft-PCI). Seventy-five patients with graft-PCI had completely occluded NVs, failed opening due to diffuse lesions or unlikely opening, as determined by the surgeon. The mean follow-up time was 37 months, during which the incidence of MACEs was $33.2 \%$ (mortality, 6.4\%; MI, 6.8\%; TVR, 20.2\%). The NV-PCI group had an improved prognosis and higher MACE-free and revascularization-free survival compared with the graft-PCI group. We thus recommend that NV-PCI be used as the first-line treatment for post-CABG graft disease. In the case of failed NV-PCI, graft-PCI can be considered.

The two major types of stents available for PCI following CABG are BMSs and DESs. Re-stenosis can significantly affect the efficacy of SVG-PCI (30). A meta-analysis revealed DESs to be superior to BMSs in SVG-PCI (31). Hakeem et al (31) analyzed 29 studies with a total of 7,994 patients (4,187 with DESs and 3,807 with BMSs) and a mean follow-up time of 6-48 months. In their meta-analysis, DESs were found to be superior to BMSs with regard to the incidence rates of MACEs (19 vs. 28\%, P<0.00001), mortality
(7.8 vs. $9 \%, \mathrm{P}=0.02)$, $\mathrm{MI}(5.7$ vs. $7.6 \%, \mathrm{P}=0.007)$ and TVR (12 vs. $17 \%, \mathrm{P}=0.0002$ ), demonstrating a higher safety and efficacy. In addition, compared with BMSs, DESs had significantly lower incidences of mortality (OR, 0.68; 95\% CI, 0.53-0.88; $\mathrm{P}=0.004)$, MACEs (OR, 0.64; 95\% CI, 0.51-0.82; $\mathrm{P}<0.001$ ), TLR (OR, 0.6; 95\% CI, 0.43-0.83; $\mathrm{P}=0.002$ ) and target vessel failure $(\mathrm{OR}, 0.57 ; 95 \% \mathrm{CI}, 0.41-0.80$; $\mathrm{P}=0.001$ ) (31). By contrast, other studies did not find DESs to be superior to BMSs in the long-term follow-up subsequent to SVG-PCI $(17,32,33)$. The SOS study (17) found that the overall mortality rate did not differ significantly between the DES and BMS groups at the end of 1.5 years of follow-up (5 vs. $12 \%$; HR, 1.56; 95\% CI, 0.72-4.11; $\mathrm{P}=0.27$ ). In a study of 284 patients with DESs and 95 patients with BMSs, the incidence of MACEs at 3 years did not differ significantly between the groups, despite a significantly higher inpatient mortality rate in the BMS group. This suggested a good safety profile (but non-superiority) of DESs in long-term implantation (33).

In the present study, DESs were employed in 239 patients $(82.7 \%)$ and BMSs in 50 patients (17.3\%), who were followed up for a mean period of 37 months. There was a trend towards an improved outcome in the DES group compared with the BMS group. In patients undergoing NV-PCI, DESs were superior to BMSs with regard to the incidence rates of MACEs and TVR, but no significant differences in mortality and MI were found between the groups. In patients undergoing graft-PCI, DESs were implanted in 56 patients and BMSs in 19 patients. The DES group showed a tendency for lower incidence rates of MACEs, cardiac mortality, MI and TVR.

It should be acknowledged that there were several limitations to the present study. Firstly, the design of the study was retrospective and non-randomized, and the course of treatment was determined by the individual surgeon. Secondly, antiplatelet treatment was administered for a variable duration and there was a lack of routine angiographic follow-up. Additionally, the length of the time-frame for inclusion in this study (5 years) may have introduced confounding effects as a 
result of developments in techniques and equipment. Finally, the use of BMSs in the graft-PCI procedures was relatively low. A prospective, randomized study with angiographic follow-up is therefore warranted to control for confounding factors. Despite these limitations, however, the present study has collated the information for a large patient population and reports the clinical presentation and outcomes of SVG disease treatment in routine, daily practice.

In conclusion, NV-PCI has an improved long-term prognosis compared with graft-PCI in the treatment of post-CABG graft disease. NV-PCI should be considered as the first-line treatment for graft lesions, but graft-PCI remains a viable option. There is insufficient data on the long-term efficacy and safety of DESs and BMSs in SVG-PCI; however, compared with BMSs, DESs are currently the preferred stents for SVG-PCI.

\section{Acknowledgements}

The authors would like to thank the Department of Catheter Laboratory and Cardiac Surgery, Tianjin Chest Hospital, for their helpful suggestions in the preparation of this study.

\section{References}

1. Lee MS, Park SJ, Kandzari DE, et al: Saphenous vein graft intervention. JACC Cardiovasc Interv 8: 831-843, 2011.

2. Campeau L, Enjalbert M, Lespérance J, Vaislic C, Grondin CM and Bourassa MG: Atherosclerosis and late closure of aortocoronary saphenous vein grafts: Sequential angiographic studies at 2 weeks, 1 year, 5 to 7 years, and 10 to 12 years after surgery. Circulation 68: II1-II7, 1983.

3. Fitzgibbon GM, Leach AJ, Kafka HP and Keon WJ: Coronary bypass graft fate: longerm angiographic study. J Am Coll Cardiol 17: 1075-1080, 1991.

4. Weintraub WS, Jones EL, Craver JM and Guyton RA: Frequency of repeat coronary bypass or coronary angioplasty after coronary artery bypass surgery using saphenous venous grafts. Am J Cardiol 73: 103-112, 1994.

5. Goldman S, Zadina K, Moritz T, Ovitt T, Sethi G, Copeland JG, et al; VA Cooperative Study Group \#207/297/364: Long-term patency of saphenous vein and left internal mammary artery grafts after coronary bypass surgery: results from a Department of Veterans Affairs Cooperative Study. J Am Coll Cardiol 44: 2149-2156, 2004.

6. Fitzgibbon GM, Kafka HP, Leach AJ, Keon WJ, Hooper GD and Burton JR: Coronary bypass graft fate and patient outcome: angiographie follow-up of 5,065 grafts related to survival and reoperation in 1,388 patients during 25 years. J Am Coll Cardiol 28: 616-626, 1996.

7. Eagle KA, Guyton RA, Davidoff R, et al; American College of Cardiology; American Heart Association: ACC/AHA 2004 guideline update for coronary artery bypass graft surgery: A report of the American College of Cardiology/American Heart Association Task Force on Practice Guidelines (Committee to Update the 1999 Guidelines for Coronary Artery Bypass Graft Surgery). Circulation 110: e340-e437, 2004.

8. Baim DS: Percutaneous treatment of saphenous vein graft disease: The ongoing challenge. J Am Coll Cardiol 42: 1370-1372, 2003.

9. Baldwin DE, Abbott JD, Trost JC, et al: Comparison of drug-eluting and bare metal stents for saphenous vein graft lesions (from the National Heart, Lung, and Blood Institute Dynamic Registry). Am J Cardiol 106: 946-951, 2010.

10. Gyenes G, Norris CM, Graham MM; APPROACH Investigators: Percutaneous revascularization improves outcomes in patients with prior coronary artery bypass surgery. Catheter Cardiovasc Interv 82: E148-E154, 2013.

11. Hiscock M, Oqueli E and Dick R: Percutaneous saphenous vein graft intervention - a review. Heart Lung Circ 16: S51-S55, 2007.
12. Sabik JF III, Blackstone E, Gillinoy M, Smedira NG and Lytle BW: Occurrence and risk factors for reintervention after coronary artery bypass grafting. Circulation 114: I454-I460, 2006.

13. Pucelikova T, Mehran R, Kirtane A, et al: Short- and long-term outcomes after stent-assisted percutaneous treatment of saphenous vein grafts in the drug-eluting stent era. Am J Cardiol 101: 63-68, 2008

14. Meliga E, García-García H, Kukreja N, et al: Chronic total occlusion treatment in post-CABG patients: Saphenous vein graft versus native vessel recanalization-long-term follow-up in the drug-eluting stent era. Catheter Cardiovasc Interv 70: 21-25, 2007.

15. Hoffmann R, Hamm C, Nienaber CA, et al; German Cypher Registry: Implantation of sirolimus-eluting stents in saphenous vein grafts is associated with high clinical follow-up event rates compared with treatment of native vessels. Coron Artery Dis 18: 559-564, 2007.

16. Vermeesch P, Agostoni P, Verheye S, et al; DELAYED RRISC (Death and Events at Long-term follow-up AnalYsis: Extended Duration of the Reduction of Restenosis In Saphenous vein grafts with Cypher stent) Investigators: Increased late mortality after sirolimus-eluting stents versus bare-metal stents in diseased saphenous vein grafts: Results from the randomized DELAYED RRISC Trial. J Am Coll Cardiol 50: 261-267, 2007.

17. Brilakis ES, Lichtenwalter C, de Lemos JA, Roesle M, Obel $\mathrm{O}$, Haagen $\mathrm{D}$, et al: A randomized controlled trial of a paclitaxel-eluting stent versus a similar bare-metal stent in saphenous vein graft lesions the SOS (Stenting of Saphenous Vein Grafts) trial. J Am Coll Cardiol 53: 919-928, 2009.

18. Mauri L, Kereiakes DJ, Yeh RW, et al; DAPT Study Investigators: Twelve or 30 months of dual antiplatelet therapy after drug-eluting stents. N Engl J Med 371: 2155-2166, 2014.

19. Morrison DA, Sethi G, Sacks J, et al; Investigators of the Department of Veterans Affairs Cooperative Study \#385, angina With Extremely Serious Operative Mortality Evaluation (AWESOME): Percutaneous coronary interventions versus coronary bypass graft surgery for patients with medically refractory myocardial ischemia and risk factors for adverse outcomes with bypass. The VA AWESOME Multicenter Registry: Comparison With the Randomized Clinical Trial. J Am Coll Cardiol 39: 266-273, 2002.

20. Yap CH, Sposato L, Akowuah E, et al: Contemporary results show repeat coronary artery bypass grafting remains a risk factor for operative mortality. Ann Thorac Surg 87: 1386-1391, 2009.

21. Runyan D, Gorges R, Feldman D, McCullough PA, David S and Saba S: Long-term follow-up of lesion-specific outcomes comparing drug-eluting stents and bare metal stents in diseased saphenous vein grafts. Rev Cardiovasc Med 14: 1-6, 2013.

22. Gupta S and Cigarroa JE: The quest for optimal interventional strategy in saphenous vein graft interventions - are we there yet? Catheter Cardiovasc Interv 80: 1118-1119, 2012.

23. Brilakis ES, Rao SV, Banerjee S, et al: Percutaneous coronaryintervention in native arteries versus bypass grafts in prior coronary artery bypass grafting patients: a report from the National Cardiovascular Data Registry. JACC Cardiovase Interv 4: 844-850, 2011.

24. Ko DT, Guo H, Wijeysundera HC, Zia MI, Džavík V, Chu MW, et al: Long-term safety and effectiveness of drug-eluting stents for the treatment of saphenous vein grafts disease: a population-based study. JACC Cardiovasc Interv 4: 965-973, 2011.

25. Hindnavis V, Cho SH and Goldberg S: Saphenous vein graft intervention: a review. J Invasive Cardiol 24: 64-71, 2012.

26. Ho PC, Lee AC and Fortuna R: Drug-eluting stenting of saphenous vein graft versus native coronary artery supplying the same myocardial perfusion territory: a pilot retrospective 3-year follow-up. J Invasive Cardiol 24: 516-520, 2012.

27. de Feyter PJ, van Suylen RJ, de Jaegere PP, Topol EJ and Serruys PW: Balloon angioplasty for the treatment of lesions in saphenous vein bypass grafts. J Am Coll Cardiol 21: 1539-1549, 1993.

28. Xanthopoulou I, Davlouros P, Tsigkas G, Panagiotou A, Hahalis G and Alexopoulos D: Long-term clinical outcome after percutaneous coronary intervention in grafts vs native vessels in patients with previous coronary artery bypass grafting. Can J Cardiol 27: 716-724, 2011. 
29. Leal S, Campante Teles R, Calé R, Sousa PJ, Brito J, Raposo L, et al; ACROSS Registry Investigators: Percutaneous revascularization strategies in saphenous vein graft lesions: long-term results. Rev Port Cardiol 31: 11-18, 2012.

30. Vermeersch P, Agostoni P, et al: Randomized double-blind comparison of sirolimus-eluting stent versus bare-metal stent implantation in diseased saphenous vein grafts: six-month angiographic, intravascular ultrasound and clinical follow-up of the RRISC Trial. J Am Coll Cardiol 48: 2423-2431, 2006.

31. Hakeem A, Helmy T, Munsif S, Bhatti S, Mazraeshahi R, Cilingiroglu M, et al: Safety and efficacy of drug eluting stents compared with bare metal stents for saphenous vein graft interventions: a comprehensive meta-analysis of randomized trials and observational studies comprising 7,994 patients. Catheter Cardiovasc Interv 77: 343-355, 2011.
32. Lozano I, García-Camarero T, Carrillo P, Baz JA, de la Torre JM, López-Palop R, et al: Comparison of drug-eluting and bare metal stents in saphenous vein grafts. Immediate and long-term results. Rev Esp Cardiol 62: 39-47, 2009 (In Spanish).

33. Goswami NJ, Gaffigan M, Berrio G, Plessa AL, Pfeiffer AM, Markwell SJ and Mishkel GJ: Long-term outcomes of drug-eluting stents versus bare-metal stents in saphenous vein graft disease: results from the Prairie 'Real World' Stent Registry. Catheter Cardiovasc Interv 75: 93-100, 2010. 